\title{
Aptidão agroclimática do pinhão manso na região de Tangará da Serra, $\mathbf{M T}^{1}$
}

\author{
Agroclimatic aptitude of oil seed plant in the region of Tangará da Serra, Mato \\ Grosso state, Brazil
}

\author{
Rivanildo Dallacort ${ }^{2 *}$, Juliano Araujo Martins ${ }^{3}$, Miriam Hiroko Inoue ${ }^{4}$, Paulo Sérgio Lourenço de Freitas ${ }^{5}$ e \\ Willian Krause ${ }^{6}$
}

\begin{abstract}
Resumo - O objetivo do presente trabalho foi determinar a aptidão agroclimática da cultura do pinhão manso (Jatropha curcas) na região de Tangará da Serra. Utilizaram-se históricos de dados diários de precipitação e temperatura do ar, disponibilizados pelo Instituto Nacional de Meteorologia (INMET) e Agência Nacional de Águas (ANA), analisando-os conforme as exigências climáticas da cultura. A região em estudo demonstrou características favoráveis ao desenvolvimento do pinhão manso, com precipitação média anual variando de $1.260,1 \mathrm{~mm}$ a $1.815,5 \mathrm{~mm}$ e temperatura média entre $24,4{ }^{\circ} \mathrm{C}$ e $26,1^{\circ} \mathrm{C}$. A temperatura média mensal encontra-se nos níveis ideais da cultura, mas o regime pluviométrico mensal indica períodos longos de baixos níveis de precipitação, principalmente durante os meses de junho, julho e agosto, com média inferior a 30 mm. De modo geral a região em estudo é classificada com aptidão plena para o cultivo do pinhão manso, no entanto, a utilização de tecnologias de irrigação pode maximizar a produtividade, uma vez que o regime hídrico é um elemento climático limitante em alguns períodos do ano.
\end{abstract}

Palavras-chave - Jatropha curcas. Aptidão agrícola. Clima.

\begin{abstract}
This study aimed to determine the agroclimatic aptitude of oil seed plant Jatropha curcas, on the region of Tangará da Serra, Mato Grosso state, Brazil. Were utilized daily historic data of rainfall and temperature provided by the National Institute of Meteorology (INMET) and National Water Agency (ANA), comparing them with specific climate demandings of the culture. The studied region demonstrated favorable characteristics to the development of Jatropha curcas, with average yearly rainfall ranging from $1,260.11$ to $1,815.5 \mathrm{~mm}$ and average temperature between $24.4{ }^{\circ} \mathrm{C}$ and $26.1{ }^{\circ} \mathrm{C}$. The monthly average temperature does not exceed in any period the ideal levels for the crop, however, the monthly rainfall indicates long periods of low rainfall, mainly during the months of June, July and August, with average below $30 \mathrm{~mm}$. The region under study is classified as fully capable for the cultivation of Jatropha curcas, though, the use of irrigation technologies can maximize the production of this oil seed plant, since the water regime is the only limiting climatic element in some periods of the year.
\end{abstract}

Key words - Jatropha curcas. Agricultural acquirement. Climate.

\footnotetext{
* Autor para correspondência

${ }^{1}$ Recebido para publicação em 23/12/2009; aprovado em 21/07/2010

Projeto de Pesquisa financiado pela Fundação de Amparo a Pesquisa do Estado de Mato Grosso/FAPEMAT

${ }^{2}$ Departamento de Agronomia/UNEMAT, Campus Universitário de Tangará da Serra, Rod. MT 358 km 7, Caixa Postal 287, Tangará da Serra-MT, Brasil, 78.300-000, rivanildo@unemat.br

${ }^{3}$ Acadêmico em Agronomia Universidade do Estado de Mato Grosso/UNEMAT, Tangará da Serra-MT, Brasil, julianoaraujo@usp.br

${ }^{4}$ Universidade do Estado de Mato Grosso, Campus Universitário de Tangará da Serra, Tangará da Serra-MT, Brasil, mirianhinoue@hotmail.com

${ }_{5}^{5}$ Programa de Pós-Graduação em Agronomia, CCA/UEM, Maringá-PR, Brasil, pslfreitas@uem.br

${ }^{6}$ Departamento de Agronomia, Universidade do Estado de Mato Grosso, Campus Universitário de Tangará da Serra-MT, Brasil, krause@unemat.br
} 


\section{Introdução}

O pinhão-manso (Jatropha curcas L.) é uma cultura com amplo potencial agrícola, destacando-se pela alta produtividade e qualidade satisfatória do óleo para produção de biodiesel. Há pouco tempo despertou interesse comercial no país, por apresentar características desejáveis tanto na renovação da base energética nacional como na agricultura familiar, favorecendo a permanência do homem no campo (MONTEIRO 2007; TEIXEIRA 2005).

Segundo Laviola e Dias (2008), a cultura do pinhão manso é uma espécie perene, pertencente à família das Euforbiáceas, a mesma da mamona, mandioca e seringueira. Sua fase reprodutiva inicia-se a partir do décimo mês após o plantio, período em que ocorre aumento progressivo de produção até o terceiro ou quarto ano, quando se estabiliza, podendo chegar a quatro metros de altura e manter o período produtivo até 40 anos (ARRUDA et al., 2004; MARTINS et al., 2008; OLIVEIRA et al., 2007).

Um dos primeiros passos a serem delimitados diante a domesticação de uma espécie, é a determinação do nível de aptidão agrícola para a região específica, o que exige um levantamento, organização e análise de dados climáticos peculiares as necessidades de tal cultura (SEDIYAMA et al., 2001). A realização do zoneamento agrícola de uma região visa obter maiores informações sobre a adaptabilidade das culturas selecionadas e, sobretudo, proporcionar maior retorno dos investimentos a médio e longo prazo para os produtores, auxiliando desta forma uma agricultura racional e sustentável (NUNES et al., 2007). Segundo Teixeira (2005), a cultura apresenta capacidade de recuperação de áreas degradadas em função de suas raízes profundas.

Por se tratar de uma espécie pouco exigente em condições climáticas e fertilidade do solo, possui grande adaptabilidade em diversas regiões, não tolera geada forte, mas pode sobreviver a geadas fracas, perdendo todas as folhas, o que provavelmente reduzirá a produção (SATURNINO et al., 2005). Severino et al. (2007) apontam a cultura com adaptada a diversas regiões do
Brasil, sendo a mesma facilmente propagada por sementes e mudas (DATTA; PANDEY, 2005).

O desenvolvimento do pinhão manso é favorecido em regiões tropicais onde a precipitação anual esteja acima de $600 \mathrm{~mm}$, sendo acima dos $1000 \mathrm{~mm}$ anuais o nível ideal de precipitação para que se possa atingir altas produtividades. Avaliando a primeira colheita, Drumond et al. (2007) obtiveram produtividade de $871 \mathrm{~kg} \mathrm{ha}^{-1} \mathrm{em}$ plantas irrigadas e, em regime normal de chuvas (sequeiro), $246 \mathrm{~kg} \mathrm{ha}^{-1}$. A produção é drasticamente afetada com valores anuais inferiores a $600 \mathrm{~mm}$ (HENNING, 1996).

Com relação à temperatura a faixa ótima de desenvolvimento para o pinhão manso varia entre $18 \mathrm{e}$ $28,5^{\circ} \mathrm{C}$ (SATURNINO et al., 2005). Andrade et al. (2007) determinaram a probabilidade de ocorrência de geadas severas ou fracas no estado do Paraná, o que possibilitou a indicação de regiões limítrofes ao cultivo do pinhão manso, uma vez que a cultura é pouco tolerante a geadas e a temperatura letal para a cultura do pinhão manso é de -3 a $-4{ }^{\circ} \mathrm{C}$ (ANDRADE et. al. 2008).

Gonçalves e Sentelhas (2008) propuseram diferentes classes de aptidão agroclimática para o pinhão manso no Estado da Bahia, analisando a distribuição das chuvas, regime de temperatura e probabilidade de ocorrência de geadas.

O presente trabalho objetivou determinar a adaptabilidade agroclimática da cultura do pinhão manso na região de Tangará da Serra, Médio Norte do Estado do Mato Grosso, por meio de análise dos elementos temperatura do ar e precipitação pluvial.

\section{Material e métodos}

A determinação da aptidão agroclimática baseou-se nos dados meteorológicos disponibilizados pelo Instituto Nacional de Meteorologia (INMET) e pluviométricos de estações da Agência Nacional de Águas (ANA), localizadas nas coordenadas geográficas referenciadas na Tabela 1.

Tabela 1 - Dados meteorológicos utilizados na determinação da aptidão agroclimática da cultura do pinhão manso

\begin{tabular}{lccccc}
\hline \multicolumn{1}{c}{ Órgão } & Referência & Latitude & Longitude & Altitude $(\mathrm{m})$ & Período \\
\hline INMET & Cáceres & $16^{\circ} 03^{\prime} \mathrm{S}$ & $57^{\circ} 41^{\prime} \mathrm{W}$ & 118,0 & 1961 a 2008 \\
ANA & Campo Novo do Parecis & $13^{\circ} 38^{\prime} \mathrm{S}$ & $58^{\circ} 17^{\prime} \mathrm{W}$ & 596,0 & 1984 a 2008 \\
INMET & Campo Novo do Parecis & $13^{\circ} 38^{\prime} \mathrm{S}$ & $57^{\circ} 60^{\prime} \mathrm{W}$ & 570,0 & 2003 a 2008 \\
INMET & Cuiabá & $15^{\circ} 33^{\prime} \mathrm{S}$ & $57^{\circ} 07^{\prime} \mathrm{W}$ & 151,3 & 1961 a 2008 \\
INMET & Diamantino & $14^{\circ} 24^{\prime} \mathrm{S}$ & $56^{\circ} 27^{\prime} \mathrm{W}$ & 286,3 & 1961 a 2008 \\
INMET & Tangará da Serra & $14^{\circ} 39^{\prime} \mathrm{S}$ & $57^{\circ} 25^{\prime} \mathrm{W}$ & 321,5 & 2003 a 2008 \\
ANA & Tangará da Serra & $14^{\circ} 38^{\prime} \mathrm{S}$ & $57^{\circ} 28^{\prime} \mathrm{W}$ & 310,0 & 1970 a 2008 \\
\hline
\end{tabular}


Para organização dos dados, verificação da consistência e determinação de médias de temperatura e precipitação para períodos mensais e anuais, utilizou-se o software CLIMA, desenvolvido pelo Instituto Agronômico do Paraná (IAPAR) (FARIA et al., 2003). As médias anuais das variáveis analisadas foram correlacionadas com a altitude local das respectivas estações, de modo a verificar a influência deste fator climático com a variação espacial dos elementos em estudo.

Com base nas exigências hídricas (HENNING, 1996) e de temperatura (SATURNINO et al., 2007), Gonçalves e Sentelhas (2008) propuseram as seguintes classes de aptidão climática para a cultura do pinhão manso: a) Apta - temperatura média anual entre 18 e $28,5{ }^{\circ} \mathrm{C}$ e chuva anual maior que $1000 \mathrm{~mm}$; b) Restrito por deficiência hídrica - temperatura média anual entre 18 e $28,5^{\circ} \mathrm{C}$ e chuva anual entre 600 e $1000 \mathrm{~mm}$; c) Restrito por deficiência térmica - risco de geadas ou temperatura média anual menor que $18,5^{\circ} \mathrm{C}$; d) Restrito por excesso de temperatura - temperatura média anual maior que $28,5{ }^{\circ} \mathrm{C}$; e) Inapta - chuva anual menor do que $600 \mathrm{~mm}$.

Tendo em vista que as médias anuais propostas como ideais para culturas perenes, consideram uma distribuição homogênea dos elementos exigidos por tal cultura durante o ano, será realizada também uma análise mensal dos elementos climáticos para determinar períodos pontuais desfavoráveis ao desenvolvimento da cultura, como períodos com baixos índices pluviométricos ou temperaturas além ou aquém da faixa considerada ideal.

\section{Resultados e discussão}

As médias anuais de precipitação, bem como a correlação obtida entre a altitude e o regime pluviométrico anual, estão apresentadas na Figura 1. O município de
Diamantino apresentou maior precipitação média anual, com 1.815,5 mm; já o município de Cáceres apresentou $1.260,1 \mathrm{~mm}$, a menor média anual (FIG. 1A). Para todas as estações, a média histórica anual apresentouse acima dos $1.000 \mathrm{~mm}$, nível considerado satisfatório para alcançar altas produtividades da cultura do pinhão manso (HENNING, 1996).

Há uma correlação entre a altitude da estação com a precipitação média anual $80,4 \%$. Com o aumento da elevação é recíproco o avanço dos níveis médios de precipitação anual (FIG. 1B). O mesmo comportamento foi observado por Carvalho e Assad (2005) em estudo realizado no estado de São Paulo.

Em relação à temperatura média anual da região (FIG. 2), observa-se que esta variou de $24,4{ }^{\circ} \mathrm{C}$ no município de Campo Novo do Parecis a $26,1{ }^{\circ} \mathrm{C}$ no município de Cuiabá (FIG. 2A). Saturnino et al. (2005) consideraram que a faixa ótima de desenvolvimento para o pinhão-manso situa-se entre $18^{\circ} \mathrm{C}$ e $28,5^{\circ} \mathrm{C}$, indicando que a variação da média anual de temperatura encontra-se na faixa ótima para o desenvolvimento da cultura durante todo ano, nas diferentes regiões consideradas.

Houve também correlação entre a temperatura e a altitude de $84,9 \%$, apresentando comportamento contrário ao da precipitação, ou seja, com o aumento da elevação houve redução da temperatura média anual entre as diferentes estações climatológicas em estudo (FIG. 2B). Resultados semelhantes foram encontrados no Estado do Paraná por Fritzsons et al. (2008) demonstrando que, com exceção da região de Foz do Iguaçu e toda região litorânea, existe uma alta correlação entre a redução das temperaturas médias em localidades de altitudes maiores.

A distribuição mensal das precipitações para os municípios de Cáceres (FIG. 3), Campo Novo do Parecis (FIG. 4), Cuiabá (FIG. 5), Diamantino (FIG. 6) e Tangará da
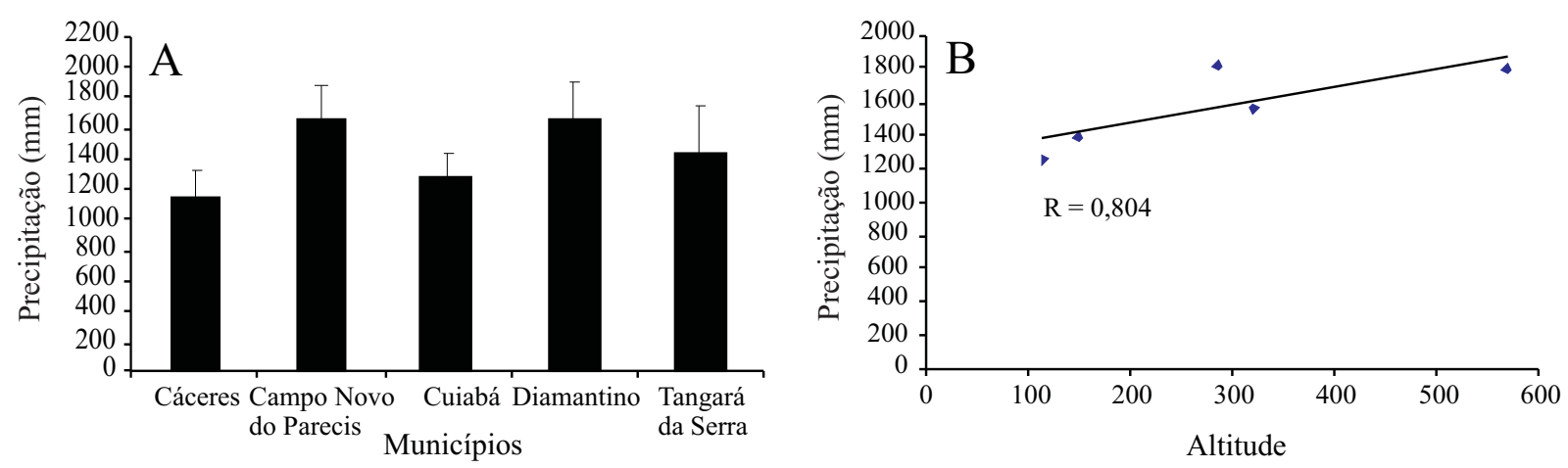

Figura 1 - Média anual de precipitação (A) e correlação da altitude com a precipitação (B) nos municípios da região Médio Norte do Estado do Mato Grosso 

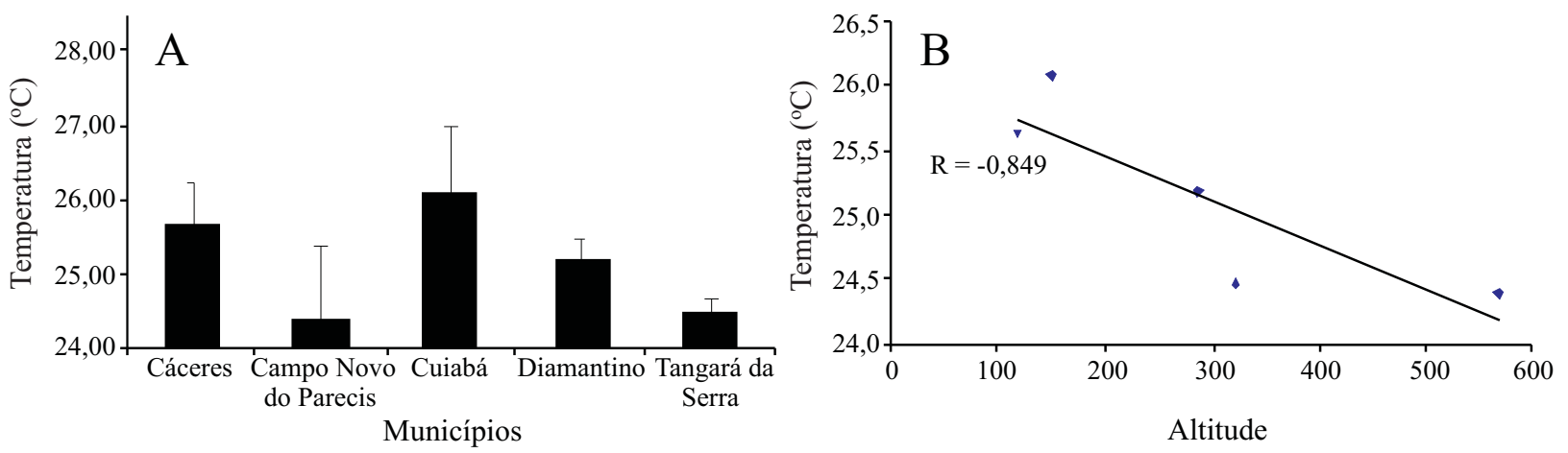

Figura 2 - Média anual de temperatura (A.) e correlação da altitude com a precipitação (B.) nos municípios da região Médio Norte do Estado do Mato Grosso

Serra (FIG. 7) indica que as regiões apresentam características semelhantes com relação à distribuição das chuvas. Observase uma estação úmida compreendendo os meses de verão, um período transitório de declínio no outono, sendo os meses de inverno com baixos índices de precipitação e posteriormente na primavera encontra-se um período transitório de elevação nos níveis de precipitação, o que, conforme Sousa (1998) é um comportamento característico da região dos cerrados.

Todos os municípios tiveram como característica, os três meses mais chuvosos (dezembro, janeiro e fevereiro), sendo registradas médias de 218,4 mm; 234,6 mm e 180,7 mm em Cáceres (FIG. 3), 269,6 mm; $321,9 \mathrm{~mm}$ e $259,3 \mathrm{~mm}$ em Campo Novo do Parecis (FIG. 4), 200,9 mm; 219,6 mm e 216,8 mm em Cuiabá (FIG. 5), $277,7 \mathrm{~mm} ; 288,9 \mathrm{~mm}$ e 288,4 mm em Diamantino (FIG. 6) e $204,3 \mathrm{~mm} ; 251,5 \mathrm{~mm}$ e $335,3 \mathrm{~mm}$ em Tangará da Serra (FIG. 7).

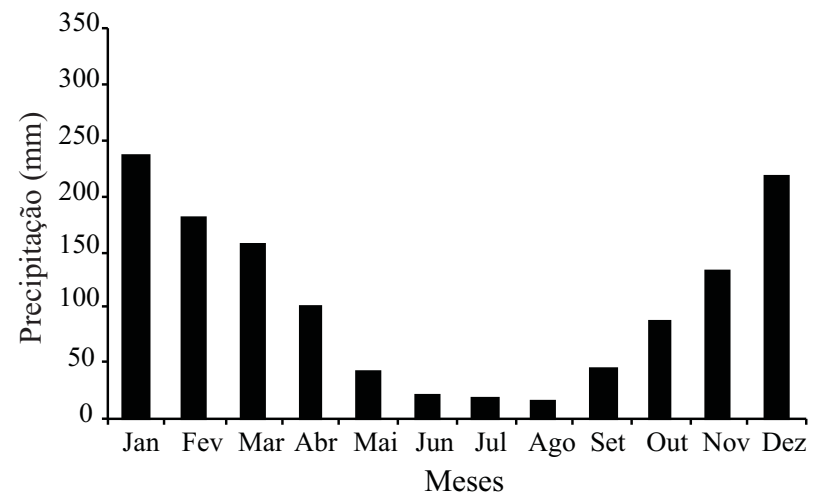

Figura 3 - Distribuição mensal da precipitação no município de Cáceres - MT, considerando a série histórica de 1961 a 2008

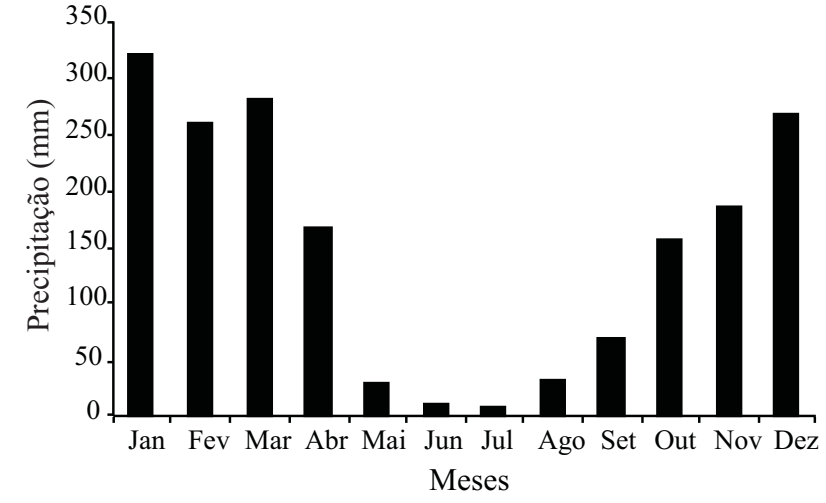

Figura 4 - Distribuição mensal da precipitação no município de Campo Novo do Parecis - MT, considerando a série histórica de 1984 a 2008

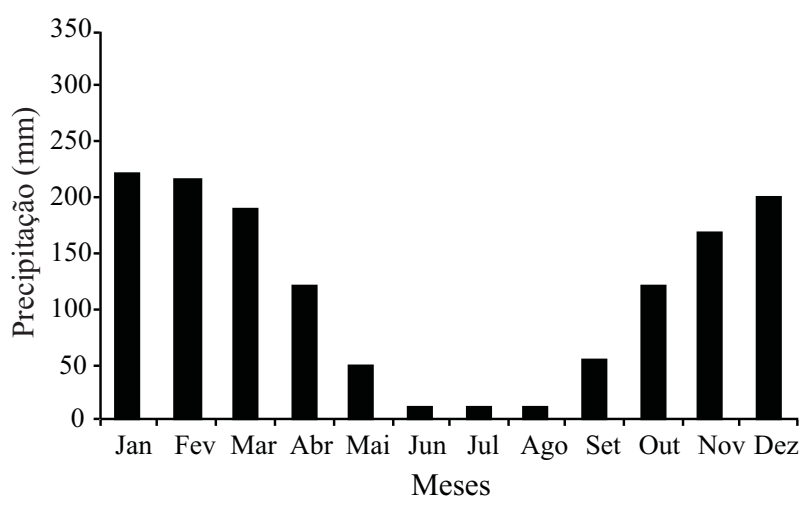

Figura 5 - Distribuição mensal da precipitação no município de Cuiabá - MT, considerando a série histórica de 1961 a 2008 


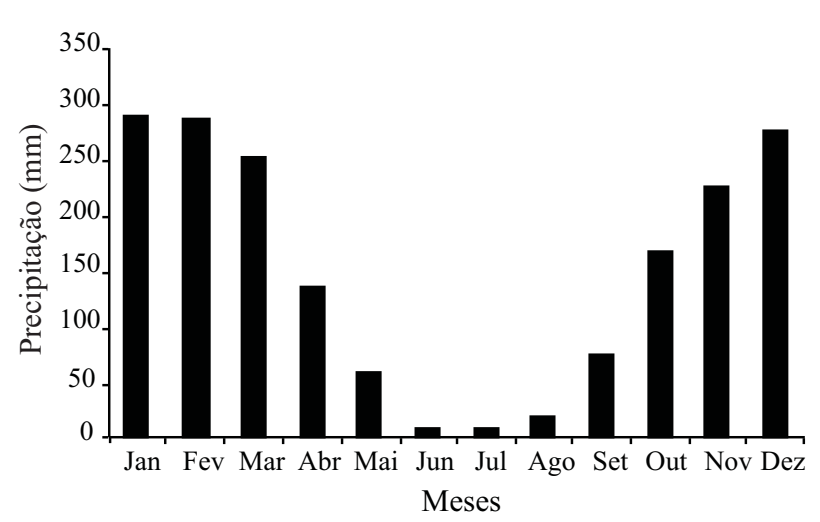

Figura 6 - Distribuição mensal da precipitação no município de Diamantino - MT, considerando a série histórica de 1961 a 2008

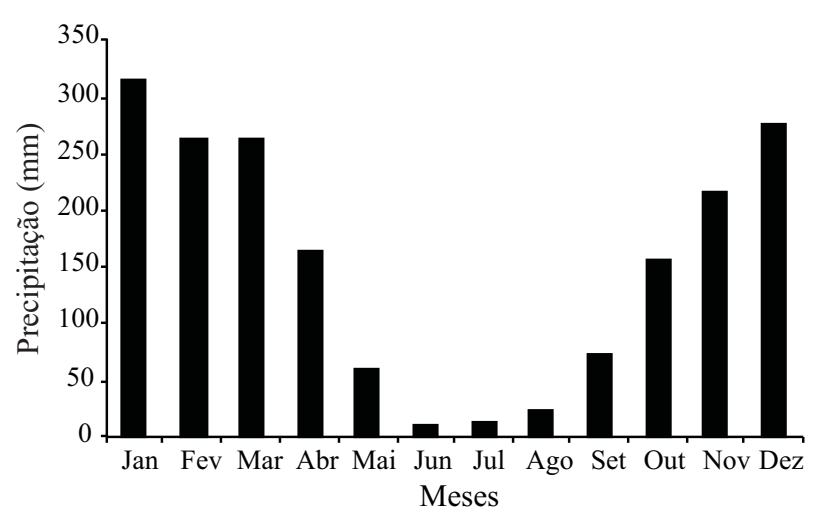

Figura 7 - Distribuição mensal da precipitação no município de Tangará da Serra - MT, considerando a série histórica de 1970 a 2008

A média mensal de precipitação nos municípios analisados apresenta uma regressão progressiva até o mês de maio, sendo registradas médias inferiores a $30 \mathrm{~mm}$ para os meses de junho, julho e agosto, caracterizando o período crítico para desenvolvimento das culturas em regime de sequeiro (FIG. 3 a 7). O pinhão manso é tolerante à seca, a grandes períodos de déficit hídrico por até três anos, no entanto a planta entra em dormência, paralisando seu crescimento e perdendo as folhas reduzindo sua produção a níveis próximos ou equivalentes a zero, passando a sobreviver da água armazenada nos caules (SATURNINO et al., 2005).

Com relação ao regime mensal de temperatura da região (FIG. 8 a 12), não existem grandes amplitudes de variação entre a média do mês mais quente para o mais frio. No município de Cáceres (FIG. 8), o mês com maior média de temperatura, corresponde a outubro, com $27,3{ }^{\circ} \mathrm{C}$, já o mês de Julho é o mais frio com média de $22,4^{\circ} \mathrm{C}$.

Nas demais localidades, Campo Novo do Parecis (FIG. 9) registrou temperaturas de $26,1^{\circ} \mathrm{C}$ em setembro e $22,8^{\circ} \mathrm{C}$ em maio; enquanto em Cuiabá (FIG. 10), o mês de outubro foi o mais quente, $\operatorname{com} 27,7^{\circ} \mathrm{C}$ e julho o mais frio com $23,3^{\circ} \mathrm{C}$. O mesmo comportamento foi observado para Diamantino (FIG. 11), com média de $26,5^{\circ} \mathrm{C}$ em outubro e $22,6^{\circ} \mathrm{C}$ em julho. Tangará da Serra (FIG. 12), também teve outubro como mês mais quente, com média de $25,5{ }^{\circ} \mathrm{C}$, no entanto o mês mais frio para esta localidade foi Maio, com média de $22,5^{\circ} \mathrm{C}$. Analisando a temperatura média mensal da região, destaca-se que em todas as localidades em questão esta variável permanece entre os níveis considerados ideais para o desenvolvimento do pinhão manso (SATURNINO et al., 2005).

As temperaturas mínimas históricas registradas nas estações meteorológicas correspondem a valores de $5,8^{\circ} \mathrm{C}$ em Cáceres, $9,2^{\circ} \mathrm{C}$ em Campo Novo do Parecis, $6,0^{\circ} \mathrm{C}$ em Cuiabá, $7,2^{\circ} \mathrm{C}$ Diamantino e $8,9^{\circ} \mathrm{C}$ em Tangará da Serra (FIG. 8 a 12). A cultura do pinhão manso não tolera geadas fortes (temperaturas no abrigo meteorológico igual ou inferiores a $0{ }^{\circ} \mathrm{C}$ ) mas sobrevive a geadas fracas (temperatura no abrigo em torno de 2 a $3{ }^{\circ} \mathrm{C}$ ), proporcionando reduções significativas na produção (ANDRADE et al., 2007). A temperatura mínima histórica já registrada nos abrigos meteorológicos corresponde ao município de Cáceres $\left(5,8{ }^{\circ} \mathrm{C}\right)$, indicando que inexiste a possibilidade de geadas na região. Conforme afirmação de Andrade et.al. (2008), a morte letal da cultura do pinhão manso ocorre com -3 a $-4{ }^{\circ} \mathrm{C}$; portanto não existe possibilidade de morte letal da planta na região em estudo devido à ocorrência de baixas temperaturas.

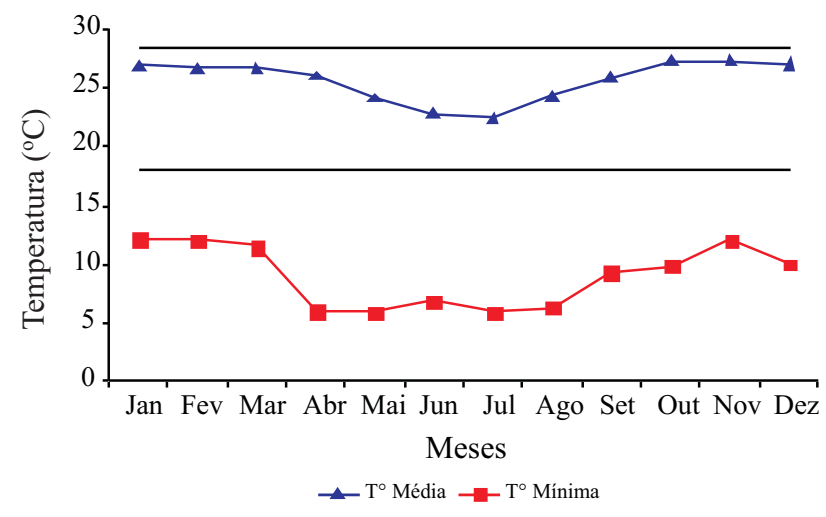

Figura 8 - Temperatura do ar média e mínima mensal no município de Cáceres - MT, considerando a série histórica de 1961 a 2008 


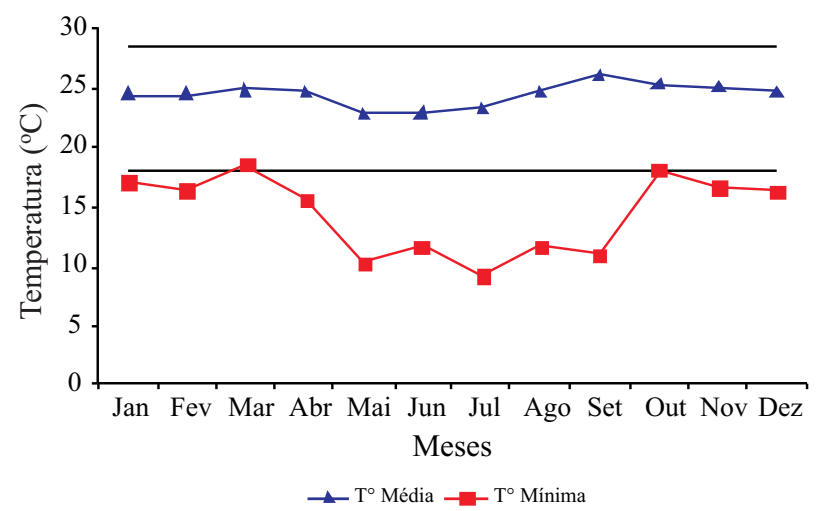

Figura 9 - Temperatura média e mínima mensal histórica no município de Campo Novo do Parecis - MT, considerando a série histórica de 2003 a 2008

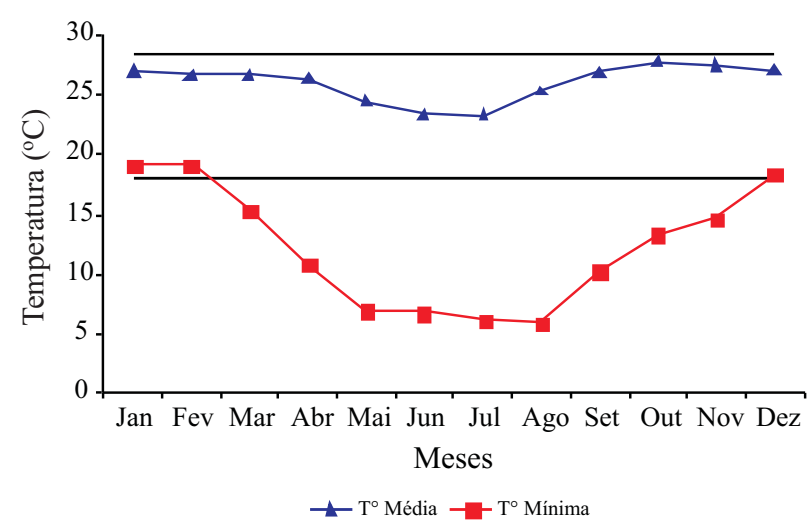

Figura 10 - Temperatura média e mínima mensal histórica no município de Cuiabá - MT, considerando a série histórica de 1961 a 2008

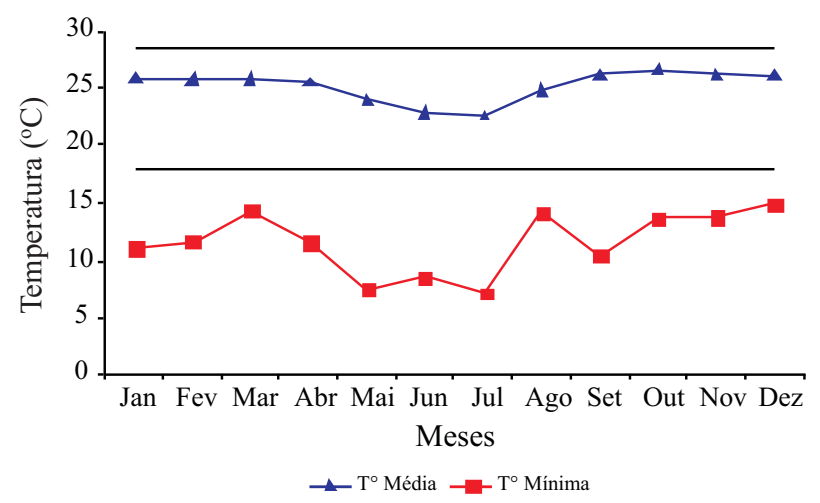

Figura 11 - Temperatura média e mínima mensal histórica no município de Diamantino - MT, considerando a série histórica de 1961 a 2008

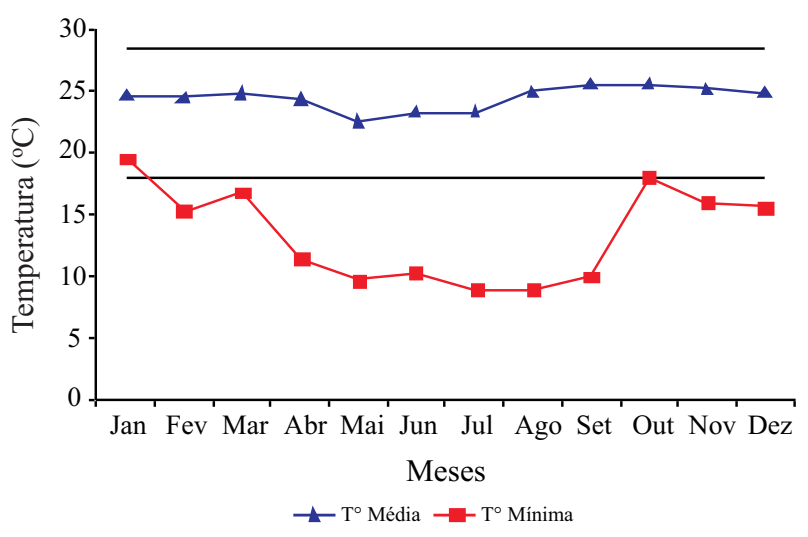

Figura 12 - Temperatura média e mínima mensal histórica no município de Tangará da Serra - MT, considerando a série histórica de 2003 a 2008

Fundamentando-se nas análises climáticas realizadas e comparando-as aos parâmetros propostos por Gonçalves e Sentelhas (2008), pode-se definir que a região estudada possui aptidão plena ao cultivo do pinhão manso, uma vez que as médias anuais de temperatura e precipitação encontram-se entre os valores considerados satisfatórios ao desenvolvimento e produção desta oleaginosa.

A temperatura média mensal não extrapola em nenhum mês a faixa ideal de desenvolvimento da cultura. A ocorrência de déficit hídrico, devido a períodos prolongados de baixa precipitação, seria o único fator climático limitante da produção do pinhão manso na região, sendo que esta questão poderá ser revertida utilizando-se de tecnologias de irrigação. Porém outras pesquisas deverão ser realizadas para investigar o grau de resposta da cultura a irrigação e a viabilidade econômica e social de tal atividade.

\section{Conclusão}

O cultivo do pinhão manso na região na região de Tangará da Serra, MT, pode ser considerado como plenamente apto baseando-se nas metodologias utilizadas para o Zoneamento desta cultura, pois a temperatura média do ar em todos os meses do ano encontra-se na faixa ideal para o desenvolvimento da cultura. A distribuição anual das chuvas na região encontra-se entre níveis considerados adequado ao desenvolvimento, no entanto a análise mensal deste elemento permite verificar a ocorrência de meses com baixos índices pluviométricos, que afetará significativamente o desenvolvimento e produção da cultura em condições de sequeiro, havendo 
a necessidade de utilização de tecnologias de irrigação para maximizar a produção da cultura nas regiões em alguns meses do ano.

\section{Agradecimentos}

À FAPEMAT - Fundação de Amparo a Pesquisa do Estado do Mato Grosso, pelo auxílio financeiro na realização do projeto de pesquisa e pela concessão de bolsas de Iniciação Científica.

\section{Referências}

ANDRADE, G. A. et al. Temperatura mínima letal para plantas jovens de pinhão-manso. Revista Bragantia, v. 67, p. 779-803, 2008.

ANDRADE, G. A. et al. Zoneamento agroclimático para a cultura do pinhão-manso (Jatropha curcas) no Estado do Paraná. Revista Brasileira de Agrometeorologia, v. 15, n. 02, p. 178-183, 2007.

ARRUDA, F. P. et al. Cultivo do Pinhão Manso (Jatrofa curcas L.) como Alternativa para o Semi-Árido Nordestino. Revista Brasileira de Oleaginosas e Fibrosas, v. 08, n. 01, p. 789-799, 2004.

CARVALHO, J. R. P.; ASSAD, E. D. Análise espacial da precipitação pluviométrica no Estado de São Paulo: comparação de métodos de interpolação. Revista Engenharia Agrícola, v. 25, n. 01, p. 377-384, 2005.

DATTA, S. K.; PANDEY, R. K. Cultivation of Jatropha curcas - a viable biodiesel source. Journal Rural Technology, v. 01, n. 06, p. 304-308, 2005.

DRUMOND, M. A. et al. Produção de pinhão manso no semiárido brasileiro. In: CONGRESSO INTERNACIONAL DE AGROENERGIA E BIOCOMBUSTÍVEIS. 2007, Teresina. Anais... Teresina, PI: Embrapa Meio Norte, 2007.

FARIA, R. T. et al. Clima - Programa computacional para organização e análise de dados meteorológicos. Revista Engenharia Agrícola, v. 23, n. 02, p. 372-387, 2003.

FRITZSONS, E.; MANTOVANI, L.E.; AGUIAR, A.V. Relação entre altitude e temperatura: Uma contribuição ao zoneamento climático no estado do Paraná. Revista de Estudos Ambientais, v. 10, n. 01, p. 49-64, 2008.
GONÇALVES, M. B.; SENTELHAS, P. C. Zoneamento agroclimático do pinhão-manso no estado da Bahia, objetivando a produção de biocombustíveis. In: UNESCO; MBC; RECYTMercosul; CNPq; PETROBRAS. (Org.). Biocombustíveis para o Mercosul. Brasília: Ministério da Ciência e Tecnologia, 2008. p. 121-140. v. 1.

HENNING, R. K. Combating desertification: The Jatrophe Project of Mali, West Àfrica. Arilands Newsletter, n. 40, 1996. Disponivel em: <http://ag.arizona.edu/OALS/ ALN/aln40/ jatropha.html $>$. Acesso em: 17 ago. 2009.

LAVIOLA, B. G.; DIAS, L. A. dos S. Acúmulo de nutrientes em folhas e frutos de pinhão-manso. Revista Brasileira de Ciência do Solo, v. 32, n. 05, p. 1969-1975, 2008.

MARTINS, C. C.; MACHADO, C. G.; CAVASINI, R. Temperatura e substrato para o teste de germinação de sementes de pinhão manso. Revista Ciência Agrotecnologia, v. 32, n. 03, p. 863-868, 2008.

MONTEIRO, J. M. G. Plantio de Oleaginosas por Agricultores Familiares do Semi-. Árido Nordestino para Produção de Biodiesel como uma Estratégia de Mitigação e. Adaptação às Mudanças Climáticas. 2007. $302 \mathrm{f}$. Tese (Doutorado em Ciências e Planejamento Energético) Universidade Federal do Rio de Janeiro, Rio de Janeiro.

NUNES, E. L. et al. Zoneamento Agroclimático da Cultura do Café para a Bacia do Rio Doce. Revista Brasileira de Meteorologia, v. 22, n. 03, p. 297-302, 2007.

OLIVERIA, R. B. de; GIMENEZ, V. M. M.; GODOY, S. A. P. de. Intoxicações com espécies da família Euphorbiaceae. Revista Brasileira de Biociências, v. 50, p. 69-71, 2007. Suplemento 01.

SATURNINO, H. M. et al. Cultura do pinhão-manso (Jatropha curcas L.). In: Produção de oleaginosas para biodiesel. Informe Agropecuário, v. 26, n. 229, p. 44-78, 2005.

SEDIYAMA, G. C. et al. Zoneamento agroclimático do cafeeiro (Coffea arabica L.) para o estado de Minas Gerais. Revista Brasileira de Agrometeorologia, v. 09, n. 03, p. 501-509, 2001.

SEVERINO, L. S.; VALE, L. S. do; BELTRÃO, N. E. de M. A simple method for measurement of jatropha curcas leaf area. Revista Brasileira de Oleainosas e Fibrosas, v. 11, n. 01, p. 9-14, 2007.

SOUSA, S. A. V. Programa computacional para simulação da ocorrência de veranicos e queda de rendimento. Pesquisa Agropecuária Brasileira, v. 33, n. 12, p. 1952-1956, 1998.

TEIXEIRA, L. C. Potencialidades de oleaginosas para produção de biodiesel. Revista Informe Agropecuário, v. 26, n. 229. p. 18-27, 2005. 